\title{
Radioprotective Nature of Podophyllum hexandrum (Himalayan Mayapple)
}

\section{Singh PK* $^{*}$}

Experimental Radiation Oncology, MD Anderson Cancer Center, Houston, Texas, USA

*Corresponding author: Singh PK, Experimental Radiation Oncology, MD Anderson Cancer Center, Houston, Texas -770030, USA, Tel: +713 745-5265; E-mail: pksingh@mdanderson.org

Rec Date: November 03, 2014; Acc date: November 03, 2014; Pub date: November 05, 2014

Copyright: ( 2014 Singh PK. This is an open-access article distributed under the terms of the Creative Commons Attribution License, which permits unrestricted use, distribution, and reproduction in any medium, provided the original author and source are credited.

\section{Introduction}

Human beings are at risk of the exposure of radiation or radioactive materials since the World War II. Nuclear proliferation and terrorist activities has further strengthened the threats of the exposure of ionizing radiation (IR) to military, civilian, and emergency responders. IR possesses sufficient energy to strip electrons from atoms or molecules and thereby create highly reactive ions. IR at high enough doses either directly or indirectly induces ionization events that damage DNA, proteins or membrane lipids, through the generation of Reactive Oxygen Species (ROS) and other free radicals intracellularly. Total Body Irradiation (TBI) is particularly dangerous when exposure is of very short period of time [1]. The Chernobyl Catastrophe and Fukushima- Daiichi nuclear plant misfortunes exemplify the need of radiation countermeasures.

Herbs have been extensively used as a medicine to heal various diseases and other upsets. Even today, more than $70 \%$ of the world's population still depends on plant-based remedies to meet their health care needs [2]. Podophyllum hexandrum Royle (Himalayan Mayapple), also called as Aindri ("a divine drug”) in ancient times, has been reported as a cure for several ailments like allergic and inflammatory conditions of the skin; cold; cancer of the brain, bladder and lung; Hodgkin's disease; mental disorders; rheumatism; septic wounds; and plague [3]. It has been reported to have the antioxidant property of $P$. hexandrum [4]. Therefore, it is reasonable to presume that $P$. hexandrum may contain groups of compounds that can protect against radiation-induced reactive oxygen species (ROS) mediated damage. $P$. hexandrum has been extensively evaluated for the radioprotective efficacy in the last decades.

$P$. hexandrum extract has been shown to render $80 \%$ total-body radioprotection in a murine model [5]. The oral administration of $P$. hexandrum has also been shown effective [6]. The radioprotective mechanism of $P$. hexandrum (rhizome extract) has been investigated using both in vitro and in vivo model systems. $P$. hexandrum exhibited potent antioxidant ability and significant free radical scavenging potential. It reduced the radiation induced lipid peroxidation [7]. We first reported that $P$. hexandrum activates heat shock transcription factor-1 (HSF-1) and MAPKAP (mitogen-activated protein kinaseactivated protein) kinase-2 leading to activation of Heat shock protein (HSP) -70 in gastrointestinal murine model [8]. Pre-treatment of mice with $P$. hexandrum activated genes responsible for cellular proliferation [Bcl-2 (B-cell chronic lymphocytic lymphoma 2), RasGAP (Ras-GTPase-activating protein) and PCNA (proliferating cell nuclear antigen). In addition, $P$. hexandrum also inhibited radiationinduced apoptosis by reducing the expression of AIF, p53, and caspase 3 [8]. Further, $P$. hexandrum inhibited the radiation induced cleavage of an inhibitor of caspase-activated DNase (ICAD) and thereby prohibited the translocation of CAD (caspase-activated
DNase) from cytoplasm to nucleus and protected DNA from CAD mediated DNA fragmentation [9].

We evaluated the role of $P$. hexandrum in cell cycle regulations and DNA repair. We observed higher expression of p21 along with lower expression of cyclin E and CDK2 in the P. hexandrum pretreated and irradiated mice as compared to irradiated mice showing delays in the G1 phase of cell cycle, which provided extra time for DNA repair or related processes [10]. No significant difference in CDK1 expression in $P$. hexandrum treated cell lines suggested that G2 arrest might not be the only responsible factor for $P$. hexandrum mediated radioprotection. Significant induction of PCNA and GADD45 expression suggested that $P$. hexandrum increased the percentage survival of HepG2 cells by increasing the span of time of DNA repair as well as efficacy of DNA repair processes.

We evaluated the effect of p53 inhibitor (pifithrin- $\alpha$ ) on the radioprotective potential of $P$. hexandrum. We observed that pifithrina debilitated the radioprotective potential of $P$. hexandrum. Pifithrin- $\alpha$ treatment reduced the radioprotective efficacy of $P$. hexandrum by inhibiting the expression of HSF-1 and Hsp70, leading to inhibition of $\mathrm{Bcl} 2$ expression required for cell proliferation [11]. Pifithrin-a upregulated the cell-cycle regulatory proteins and therefore reduced the span of time required for DNA repair. Pifithrin- $\alpha$ induced Bax mediated apoptosis. Pifithrin- $\alpha$ did not show any effect on p53 regulating protein like MDM2 and pro-survival protein like Ras-GAP [11].

In conclusion, $P$. hexandrum has the potential to be developed as a drug for the medical management of nuclear and radiological emergencies [12]. Besides the free radical scavenging activities, its holistic action at various cellular and molecular levels includes enhancement of pro-survival and DNA repair protein, downregulation of the proteins associated with apoptosis induction, modulation of cell cycle to provide extra time for cellular repairs.

\section{References}

1. Weiss JF, Landauer MR (2009) History and development of radiationprotective agents. Int J Radiat Biol 85: 539-573.

2. Wachtel-Galor S, Benzie IFF (2011) Herbal Medicine: An Introduction to Its History, Usage, Regulation, Current Trends, and Research Needs.In: Benzie IFF, Wachtel-Galor S (eds.) Herbal Medicine: Biomolecular and Clinical Aspects. (2ndedn), Boca Raton (FL): CRC Press.

3. Arora R, Gupta D, Chawla R, Sagar R, Sharma A, et al. (2005) Radioprotection by plant products: present status and future prospects. Phytother Res 19: 1-22.

4. Chawla R, Arora R, Kumar R, Sharma A, Prasad J, et al. (2005) Antioxidant activity of fractionated extracts of rhizomes of high-altitude Podophyllum hexandrum: role in radiation protection. Mol Cell Biochem 273: 193-208. 
Citation: Singh PK (2014) Radioprotective Nature of Podophyllum hexandrum (Himalayan Mayapple). Gene Technology 4: e112. doi: $10.4172 / 2329-6682.1000 \mathrm{e} 112$

Page 2 of 2

5. Goel HC, Prasad J, Sharma A, Singh B (1998) Antitumour and radioprotective action of Podophyllum hexandrum. Indian J Exp Biol 36: 583-587.

6. Gupta ML, Sankhwar S, Verma S, Devi M, Samanta N, et al. (2008) Whole body protection to lethally irradiated mice by oral administration of semipurified fraction of Podophyllum hexandrum and post irradiation treatment of Picrorhiza kurroa. Tokai J Exp Clin Med 33: 6-12.

7. Sagar RK, Chawla R, Arora R, Singh S, Krishna B, et al. (2006) Protection of the hemopoietic system by Podophyllum hexandrum against gamma radiation-induced damage. Planta Med 72: 114-120.

8. Kumar R, Singh PK, Sharma A, Prasad J, Sagar R, et al. (2005) Podophyllum hexandrum (Himalayan mayapple) extract provides radioprotection by modulating the expression of proteins associated with apoptosis. Biotechnol Appl Biochem 42: 81-92.

9. Singh PK, Kumar R, Sharma A, Arora R, Chawla R, et al. (2011) Role of Apoptotic Proteins in REC-2006 Mediated Radiation Protection in
Hepatoma Cell Lines. Evid Based Complement Alternat Med 2011: 758326.

10. Singh PK, Kumar R, Sharma A, Arora R, Chawla R, et al. (2009) Podophyllum hexandrum fraction (REC-2006) shows higher radioprotective efficacy in the p53-carrying hepatoma cell line: a role of cell cycle regulatory proteins. Integr Cancer Ther 8: 261-272.

11. Singh PK, Kumar R, Sharma A, Arora R, Jain SK, et al. (2009) Pifithrinalpha decreases the radioprotective efficacy of a Podophyllum hexandrum Himalayan mayapple fraction REC-2006 in HepG2 cells. Biotechnol Appl Biochem 54: 53-64.

12. Arora, R, et al. (2010) Podophyllum hexandrum as a potential botanical supplement for the medical management of nuclear and radiological emergencies (NREs) and free radical-mediated ailments: leads from in vitro/in vivo radioprotective efficacy evaluation. J Diet Suppl 7: 31-50. 